\title{
Aerothermodynamic Characteristics of Boundary Layer Transition and Trip Effectiveness of the HIFiRE Flight 5 Vehicle
}

\author{
Karen T. Berger ${ }^{*}$ and Shann J. Rufer ${ }^{\dagger}$ \\ NASA Langley Research Center, Hampton, VA, 23681 \\ and \\ Roger Kimmel ${ }^{*}$ and David Adamczak ${ }^{* *}$ \\ Air Vehicles Directorate, Air Force Research Laboratory, Dayton, $\mathrm{OH}$
}

\begin{abstract}
An experimental wind tunnel test was conducted in the NASA Langley Research Center's 20-Inch Mach 6 Tunnel in support of the Hypersonic International Flight Research Experimentation Program. The information in this report is focused on the Flight 5 configuration, one in a series of flight experiments. This report documents experimental measurements made over a range of Reynolds numbers and angles of attack on several scaled ceramic heat transfer models of the Flight 5 vehicle. The heat transfer rate was measured using global phosphor thermography and the resulting images and heat transfer rate distributions were used to infer the state of the boundary layer on the windside, leeside and side surfaces. Boundary layer trips were used to force the boundary layer turbulent, and a study was conducted to determine the effectiveness of the trips with various heights. The experimental data highlighted in this test report were used determine the allowable roughness height for both the windside and side surfaces of the vehicle as well as provide for future tunnel-to-tunnel comparisons.
\end{abstract}

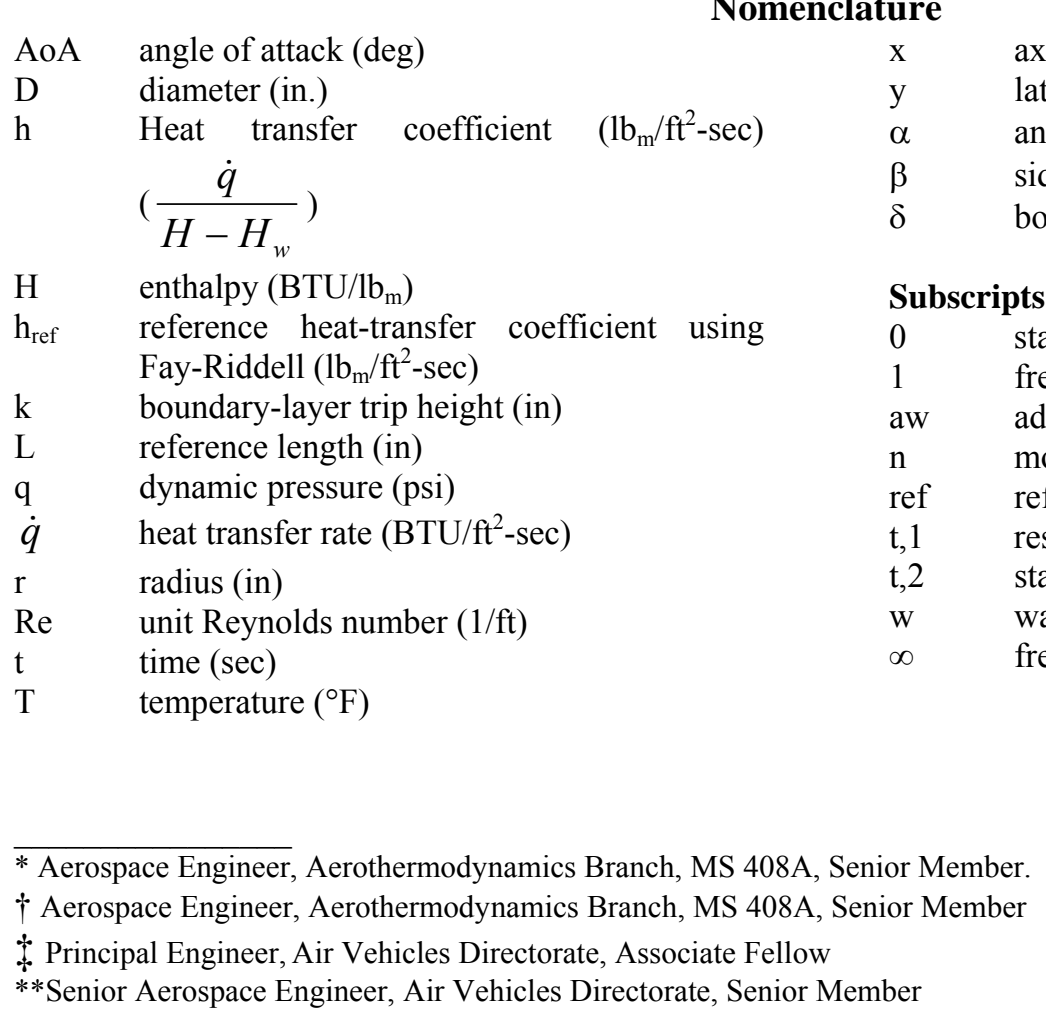

American Institute of Aeronautics and Astronautics 


\section{Introduction}

The Hypersonic International Flight Research Experimentation (HIFiRE) program is a joint hypersonic flight test program between the Air Force Research Laboratories (AFRL) and Australian Defence Science and Technology Organization (DSTO) with input from universities, private industry and NASA. The goal of the HIFiRE program is to develop and demonstrate fundamental hypersonic technologies for application to advanced scramjet powered vehicles. This will be accomplished through a series of launches incorporating flight experiments to demonstrate basic and applied research concepts for hypersonic scramjet flight. The program will span 6 years and include flights Mach 5 and above. The flight tests will be conducted primarily at the Woomera Prohibited Test Range, in Southern Australia. The primary goal of the HIFiRE Flight 5 experiment is to obtain transitional and turbulent boundary layer heating flight data on an elliptical cone.

Boundary-layer transition is an important parameter in hypersonic vehicle design. Transition impacts vehicle design primarily through aerodynamic heating but also skin friction drag and affects pressure drag, engine performance, and aerodynamic control ${ }^{1}$. Estimates for the National Aerospace Plane (NASP) ${ }^{2}$ showed that the payload-to-gross-weight ratio would nearly double if the vehicle boundary-layer were fully laminar, compared to fully turbulent.

Boundary layer transition predictions on hypersonic lifting bodies present a challenge because several modes of transition mechanisms are present. During the mid-1990s, several researchers investigated transition phenomena on elliptic cones. ${ }^{3-10}$ The elliptic cone embodies much of the transition phenomena seen on hypersonic glide vehicles. These phenomena include traveling first and second-mode waves, stationary and traveling cross-flow waves ${ }^{11}$ and leading edge attachment line flows. ${ }^{12}$ Attachment line flows contain no unique instability modes, but are characterized by thin boundary layers that are sensitive to roughness, but otherwise are generally stable. Similar to the HIFiRE 5 shape, Fig. 1 shows a cone with 2:1 elliptic cross-section in Arnold Engineering Development Center von Karman Facility Tunnel B. The model has a nominally sharp tip and the cone half-angle in the minor axis is 7 deg. Nominal freestream Mach number for this test was 8, and the ratio of wall-to-stagnation temperature $T_{w} / T_{0}=0.42$. Figure 2 shows measured heat transfer rate contours and the transition front for a shape such as the HIFiRE 5 vehicle. The plot is a composite of transition measurements made at several freestream unit Reynolds numbers and illustrates the very different stability characteristics between the centerline and leading edge. The centerline possesses a highly-inflected, unstable profile due to boundary layer fluid washing in from the higherpressure leading edges. Its transition Reynolds number is on the order of $5 \times 10^{5}$ and there are no well-defined crossflow side lobes. The leading edge, however, exhibits a transition Reynolds number near $6 \times 10^{6}$, or an order of magnitude larger. As a point of reference, transition on a 7-deg half-angle sharp, axisymmetric cone under the same conditions occurs at approximately $2.6 \times 10^{6} .^{13}$

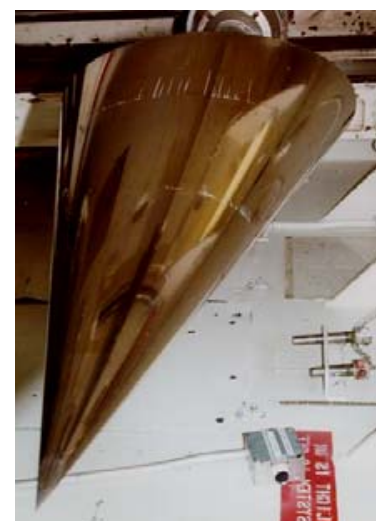

Figure 1: 2-1 Elliptical Cone

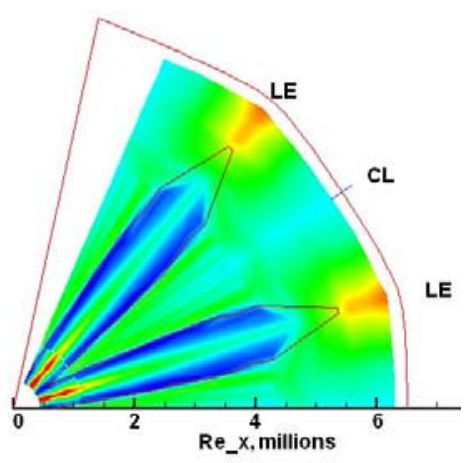

Figure 2: Heat transfer contours on unwrapped surface of elliptic cone [ref 2]. Red line indicates transition front.

The HIFiRE 5 flight will be a Mach 7.5, spin stabilized re-entry. Data will be collected through the entire flight but the useful window for boundary layer transition heating data is taken to be between an altitude of 118,000 $\mathrm{ft}$ (36 $\mathrm{km})$, when the Reynolds number on the elliptic cone will reach $1 \times 10^{6}$ and 59,000 $\mathrm{ft}(18 \mathrm{~km})$, when the vehicle is expected to depart from stable flight. This window is approximately nine sec. ${ }^{14}$

The primary objective of the test entry into the Langley Research Center (LaRC) 20-Inch Mach 6 Tunnel was to determine the overall transition pattern and roughness tolerances for the flight vehicle. Two cast ceramic wind tunnel geometries were fabricated with different nose shapes. Global phosphor thermography was used to obtain the surface heating rates at unit Reynolds numbers between $1.1 \times 10^{6} / \mathrm{ft}$ and $7.0 \times 10^{6} / \mathrm{ft}$, angles of attack from -4 to $+4 \mathrm{deg}$ 
and sideslip angles of -4 to +4 deg. Boundary layer trips were required for this test in order to determine the allowable roughness on the windside and side surfaces. The majority of the boundary layer tripping utilized a twodimensional "trip strip" to simulate a step in the nose-to-body joint. This interaction is especially important on the leading edge. Three-dimensional "diamond" shaped boundary layer trips were also utilized to simulate fasteners on a close-out panel on one side of the vehicle. It is important to ensure that any boundary layer transition associated with these protuberances will not feed around onto the smooth side of the flight vehicle. The ground test data from the HIFiRE Flight 5 configuration in the LaRC 20-Inch Mach 6 Tunnel and other facilities as well as the flight test data will be used to further the understanding of boundary layer transition prediction. This report will focus on the experimental ground test results. More information on the computational results can be found in Ref. 14 .

The experimental data collected for this test report will be used to determine the effects of roughness elements on the vehicle, including the fasteners on a closeout panel on one side as well as steps associated with the joint between the nose and body of the flight vehicle. Ground testing was used to determine the boundary layer transition trip effectiveness for these sites as well as turbulent heating patterns resulting from the discrete disturbances. The data will also be will be used as verification of computational predictions and for comparisons to data collected in other facilities. The configuration will be tested both at the Purdue Mach 6 Quiet Tunnel, where the model scale will match the LaRC model scale, as well as at CUBRC.

The HIFiRE Flight 5 is a continuation of the work completed for the HIFiRE Flight 1. The ground testing discussed in this report is similar to the ground testing completed for the HIFiRE 1 vehicle, which is a conecylinder-flare geometry. Additional information on the HIFiRE Flight 1 vehicle as well as ground testing completed in support of the program can be found in Refs. 15-19.

Model/Support Hardware

\section{Experimental Methods}

The HIFiRE Flight 5 Vehicle Outer Mold Line (OML) is a 2:1 elliptical cone with a 7 deg half angle on the minor axis, shown in Fig. 3. The elliptic cone protrudes beyond the second-stage booster in the major axis. An elliptical-to-circular transition section joins the elliptic cone test article to the cylindrical booster. All LaRC wind tunnel models were $15 \mathrm{in}$. long and the elliptic cone section as well as a portion of the transition section was modeled for the test. The flight vehicle elliptic cone will be $33.891 \mathrm{in}$. and at a model scale of $38.1 \%$, the elliptic cone has a model length of $12.91 \mathrm{in}$. Two different model configurations were fabricated for this test, each with a different nose shape. The first model will be referred to as the Baseline model and utilized the primary flight configuration for the nose. The nose tip cross-section is a circular arc with a 0.098 in. radius minor axis and 0.197 in. major axis, retaining a 2:1 elliptical cross-section to the tip. The other configuration, referred to as the Nose 1 model, is an alternate flight nose cap shape generated from tangent circular arcs in the major and minor axes. The second nose tip yielded results that were not substantially different from the baseline shape and will not be discussed further.

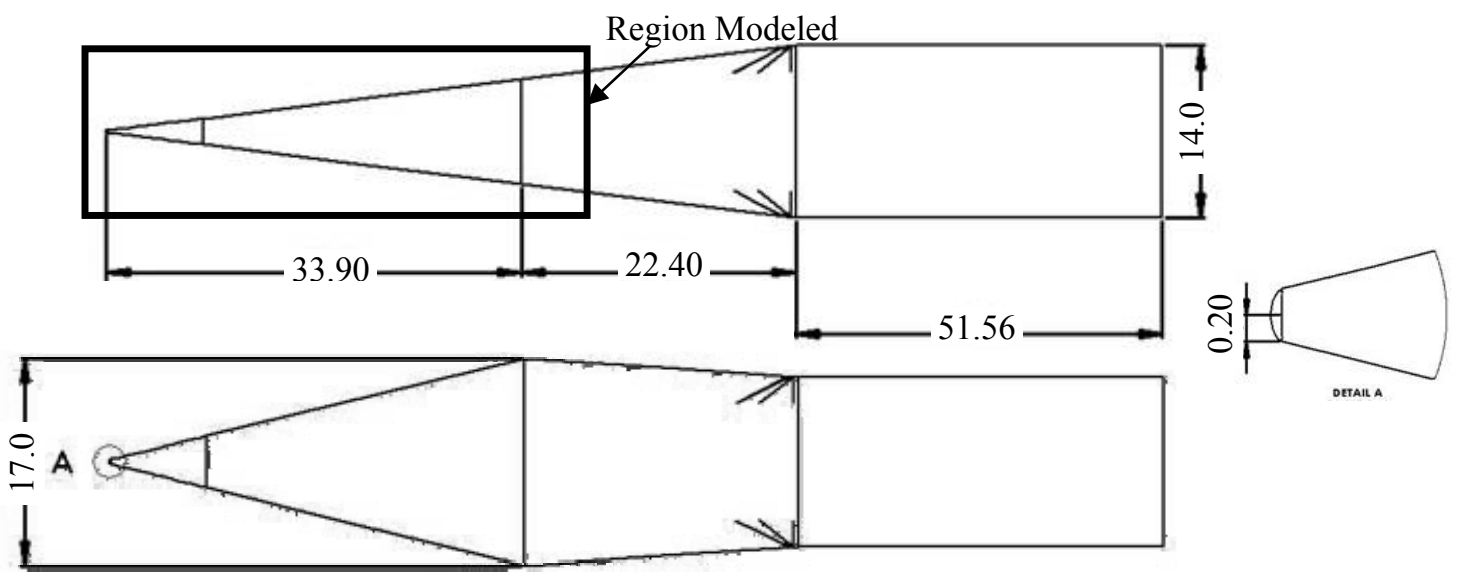

Figure 3: HIFiRE Flight 5 Vehicle (dimensions in inches)

The cast ceramic models used in the Mach 6 test series were manufactured from molds created from rapid prototyped resin patterns. Standard methods, materials, and equipment developed at NASA LaRC were used in fabricating the ceramic aeroheating test models. ${ }^{20}$ All models were supported by 1 -in. diameter cylindrical stainless steel straight stings mounted through the axis of symmetry. Fiducial marks were applied to the model surface using a 
coordinate measuring machine. These marks were then used to align the model in the tunnel for testing and to aid in data reduction using the phosphor thermography system.

Two boundary layer trip configurations were utilized in order to simulate the effects due to fasteners on the closeout panel (3-D "diamond" shaped trip) and the joint between the nose and body of the vehicle (2-D "strip" trip). The trip shapes are shown in Fig. 4. Trip heights were 0.0025 to $0.0185 \mathrm{in}$. for the 3D trips and 0.0035 to $0.0220 \mathrm{in}$. for the 2D trips. All trips were fabricated from kapton tape and were $0.05 \mathrm{in}$. wide. The diamond shaped trips were 0.05 in. squares. Except for a limited number of runs, all trips were placed at an $\mathrm{x} / \mathrm{L}$ location of 0.2 in order to represent the joint location. A small number of runs utilized trips at $\mathrm{x} / \mathrm{L}=0.5$ [note that $\mathrm{L}$ is the total model length of 15 in.]

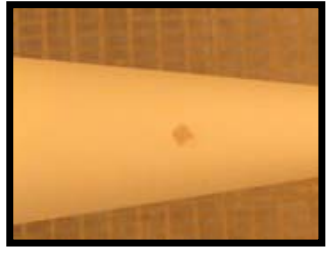

(a)

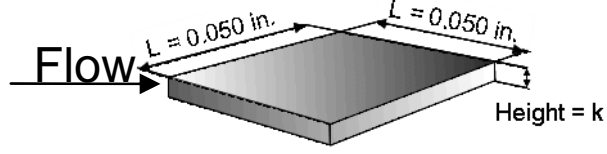

(b)

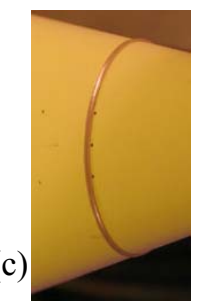

b) diamond trip

Figure 4: Boundary Layer Trips Utilized for HIFiRE 5 Testing;
dimensions, (c) strip trip

Facility

The data included in this report were obtained in the NASA Langley Aerothermodynamics Laboratory (LAL). ${ }^{21}$ The 20-Inch Mach 6 Tunnel has well characterized perfect gas flows in terms of composition and uniformity. Representative test conditions for the facility are shown in Table 1 . The values of $P_{t, 1}$ and $T_{t, 1}$ are accurate to within $\pm 2 \%$. The uncertainties in the angle of attack of the model are $\pm 0.2 \mathrm{deg}$.

20-Inch Mach 6 Tunnel: The Langley 20-Inch Mach 6 Tunnel is a blow down wind tunnel that uses dry air as the test gas. Air from two high pressure bottle fields is transferred to a 600-psia reservoir and is heated to a maximum temperature of $1000^{\circ} \mathrm{R}$ by an electrical resistance heater. A double filtering system is employed having an upstream filter capable of capturing particles larger than 20 microns and a second filter rated at 5 microns. The filters are installed between the heater and settling chamber. The settling chamber contains a perforated conical baffle at the entrance and internal screens. The maximum operating pressure is 525 psia. A fixed geometry, two-dimensional contoured nozzle is used; the top and bottom walls of the nozzle are contoured and the side walls are parallel. The nozzle throat is $0.34 \mathrm{in}$. by $20 \mathrm{in}$., the test section is $20.5 \mathrm{in}$. by $20 \mathrm{in}$., and the nozzle length from the throat to the test section window center is $7.45 \mathrm{ft}$. This tunnel is equipped with an adjustable second minimum and exhausts either into combined 41-ft diameter and 60-ft diameter vacuum spheres, a 100-ft diameter vacuum sphere, or to the atmosphere through an annular steam ejector. The maximum run time is 20 minutes with the ejector, though heating tests generally have total run times of $30 \mathrm{sec}$, with actual model residence time on tunnel centerline of approximately 5-10 sec. (data used for this test was taken at $3 \mathrm{sec}$.). Models are mounted on the injection system located in a housing below the closed test section.

\section{Experimental Methods}

Global Phosphor Thermography: The two-color relative-intensity phosphor thermography measurement technique was used to obtain global experimental aeroheating data on the model ${ }^{22-24}$. This technique uses a mixture of phosphors that fluoresce in the bands of the visible spectrum when illuminated with ultraviolet light. The red and green bands are used and the intensity of the fluorescence is dependent upon the amount of incident ultraviolet light and the local surface temperature of the phosphor. This phosphor mixture, which is suspended in a silica ceramic binder and applied with an air brush, is used to coat a slip cast silica ceramic model. The final coating thickness is approximately 0.001 in. Using a 3-CCD (Charge Coupled Device) camera, fluorescence intensity images of an illuminated phosphor model exposed to the heated hypersonic flow of the tunnel are acquired and converted to temperature mappings via a temperature-intensity calibration. The temperature-intensity calibration uses the ratio of the red and green components of the image to construct a lookup table which converts the intensities to temperature values. Currently, this calibration is valid over a temperature range from $532{ }^{\circ} \mathrm{R}$ to $800{ }^{\circ} \mathrm{R}$. The temperature data from the time-sequenced images taken during the wind tunnel run are then reduced to enthalpy based heat transfer coefficient at every pixel on the image (and hence globally on the model) using a heat-transfer calculation assuming one-dimensional semi-infinite slab heat conduction and a step function in the heat transfer coefficient, $\mathrm{h}^{23}$ 
Table 1: Representative Test Conditions for the 20-In Mach 6 Tunnel

\begin{tabular}{|c|c|c|c|c|c|c|c|c|}
\hline Tunnel & $\begin{array}{c}\mathrm{P}_{\mathrm{t}, 1,} \\
\mathrm{psi}\end{array}$ & $\begin{array}{c}\mathrm{T}_{\mathrm{t}, 1,} \\
{ }^{\circ} \mathrm{R}\end{array}$ & $\mathrm{M}_{\infty}$ & $\begin{array}{c}\mathrm{Re}_{\infty}, \\
\mathrm{ft}^{-1} \times 10^{-6}\end{array}$ & $\begin{array}{c}\mathrm{P}_{\infty}, \\
\mathrm{Psi}_{10} 10^{2}\end{array}$ & $\begin{array}{c}T_{\infty}, \\
{ }^{\circ} R\end{array}$ & $\begin{array}{c}\mathrm{q}_{\infty}, \\
\mathrm{Psi}\end{array}$ & $\begin{array}{c}\mathrm{V}_{\infty}, \\
\mathrm{ft} / \mathrm{s}\end{array}$ \\
\hline Mach 6 & 29 & 868 & 5.86 & 0.533 & 2.14 & 111.6 & 0.514 & 3020 \\
\hline Mach 6 & 59 & 882 & 5.88 & 1.046 & 4.238 & 111.7 & 1.028 & 3047 \\
\hline Mach 6 & 124 & 922 & 5.98 & 1.98 & 8.12 & 113.7 & 2.03 & 3122 \\
\hline Mach 6 & 250 & 911 & 5.99 & 4.043 & 16.116 & 111.8 & 4.051 & 3103 \\
\hline Mach 6 & 366 & 936 & 6.02 & 5.632 & 23.111 & 114.2 & 5.852 & 3142 \\
\hline Mach 6 & 476 & 930 & 6.04 & 7.383 & 29.813 & 113.1 & 7.573 & 3136 \\
\hline
\end{tabular}

Data Presentation, Quality and Uncertainty

Global heating images and corresponding centerline data distributions will be presented in the non-dimensional $\mathrm{h} / \mathrm{h}_{\text {ref }}$ format and were extracted from a two-dimensional image. The reference $\mathrm{h}$ value was based on the Fay-Riddell hemisphere stagnation point heating equation ${ }^{25}$ with a nose radius of $0.02505 \mathrm{in}$.

Uncertainties in the phosphor thermography are based on surface temperature rise, and those presented here are based on historical testing with a variety of model types. On surfaces with significant temperature rise, such as windside surfaces $\left(>70^{\circ} \mathrm{F}\right)$, uncertainties are in the range of $\pm 10 \%$. For moderate temperature rise $\left(20-30^{\circ} \mathrm{F}\right)$ such as the leeside, the uncertainties are roughly $\pm 25 \%$. More information on uncertainties in the phosphor thermography can be found in Refs. 23 and 24.

Windside Heating

\section{Test Results}

One of the primary motivators for this wind tunnel testing was the desire to determine the heating rates and boundary layer transition characteristics of the windward surface of the HIFiRE 5. The 2:1 elliptical cone shape exhibits both second-mode and crossflow instability ${ }^{14}$. Initial testing was done without trips in order to determine the smooth-body transition pattern. The transition pattern, indicated by an increase in the heat transfer rate above the laminar heating rate, at zero deg AoA exhibited a double-lobed pattern as illustrated in Fig. 5. This pattern closely resembles $\mathrm{N}$-factor contours for stationary crossflow instabilities for the sharp elliptic cone. ${ }^{14}$ Figure 6 is the 0 deg AoA case at a Reynolds number of $3.1 \times 10^{6} / \mathrm{ft}$ with a color bar range with better resolution. The jagged nature of the transition front is evident and is another property of crossflow-induced transition. On the basis of these resemblances, this transition pattern is presumed to be the result of crossflow. ${ }^{26}$ As shown in Fig. 5, the centerline heating departed from the laminar heating conditions at all unit Reynolds number tested, though at the lowest unit Reynolds number, $1.1 \times 10^{6} / \mathrm{ft}$, heating rates did not reach fully turbulent heating conditions before the end of the model. All of the other conditions reached turbulent levels (off-centerline smooth body heating rates are the same as those tripped with boundary layer trips - not shown). As the unit Reynolds number was increased, the transition moved closer to the nose of the model. As shown in the heating images for each set of data, the primary heating was off centerline. Figure 7 shows turbulent flow inboard and laminar flow outboard. As the unit Reynolds number is increased, transition moves closer to the leading edge.

A prominent feature in the images is a "cold streak" of lower heating that runs down the centerline of the model on the minor axis. This local dip in heating is probably caused by crossflow from the leeside and results in an influx of fluid from the high-pressure leading edges to low-pressure centerline. This influx causes a thick inflected boundary layer on the centerline that reduces heating ${ }^{11}$. This feature is evident in the turbulent as well as the laminar boundary layer. Generally the transition patterns are similar to those observed for the HIFiRE-5 configuration in the CUBRC LENS I wind tunnel, with the exception of leading-edge transition ${ }^{27}$, as noted in the discussion of the side surface below. It should be noted that the AEDC elliptic cone transition patterns shown in Fig. 2 show no welldefined crossflow side lobes. This may be due to the sharp nose, which might be expected to destabilize the centerline and push centerline transition upstream of crossflow transition, or simply due to a lack of resolution in the placement of sensors. 

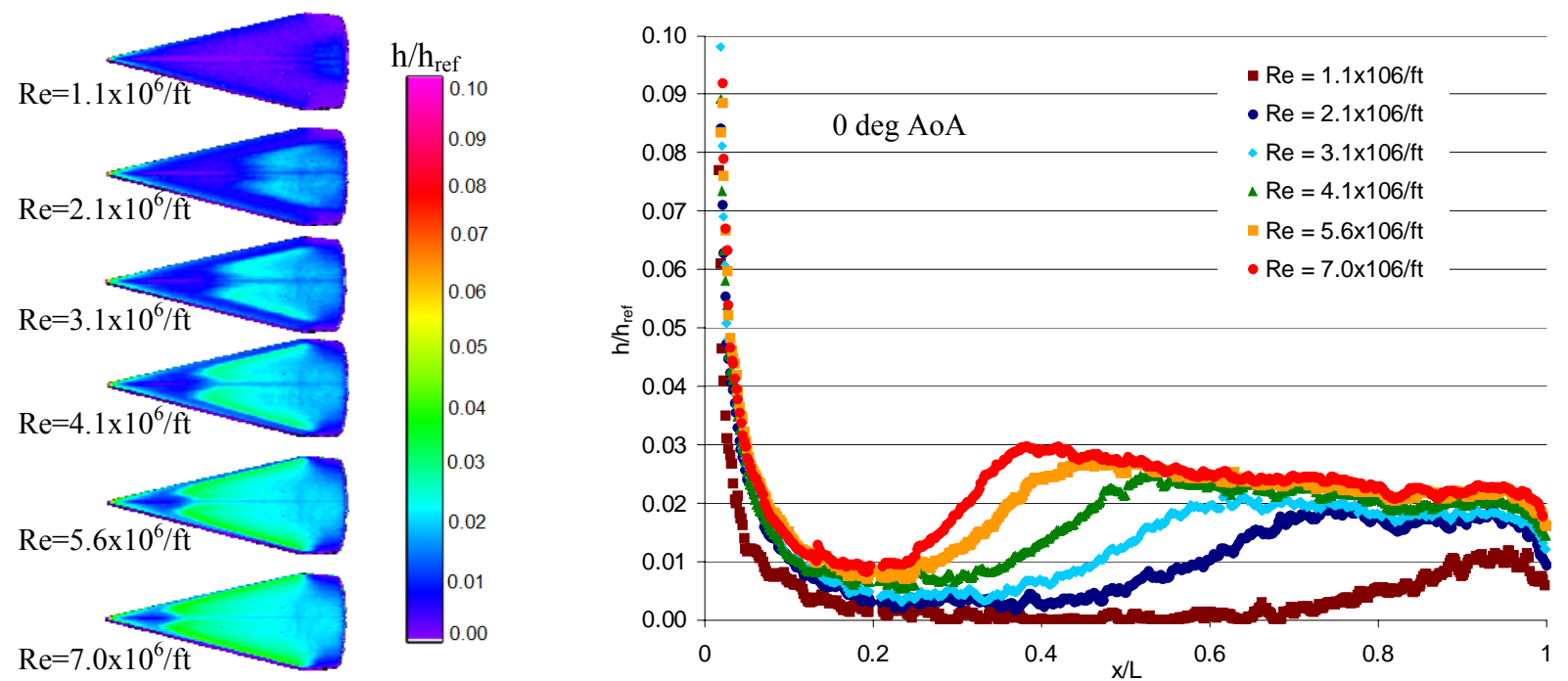

Figure 5: Centerline Heating

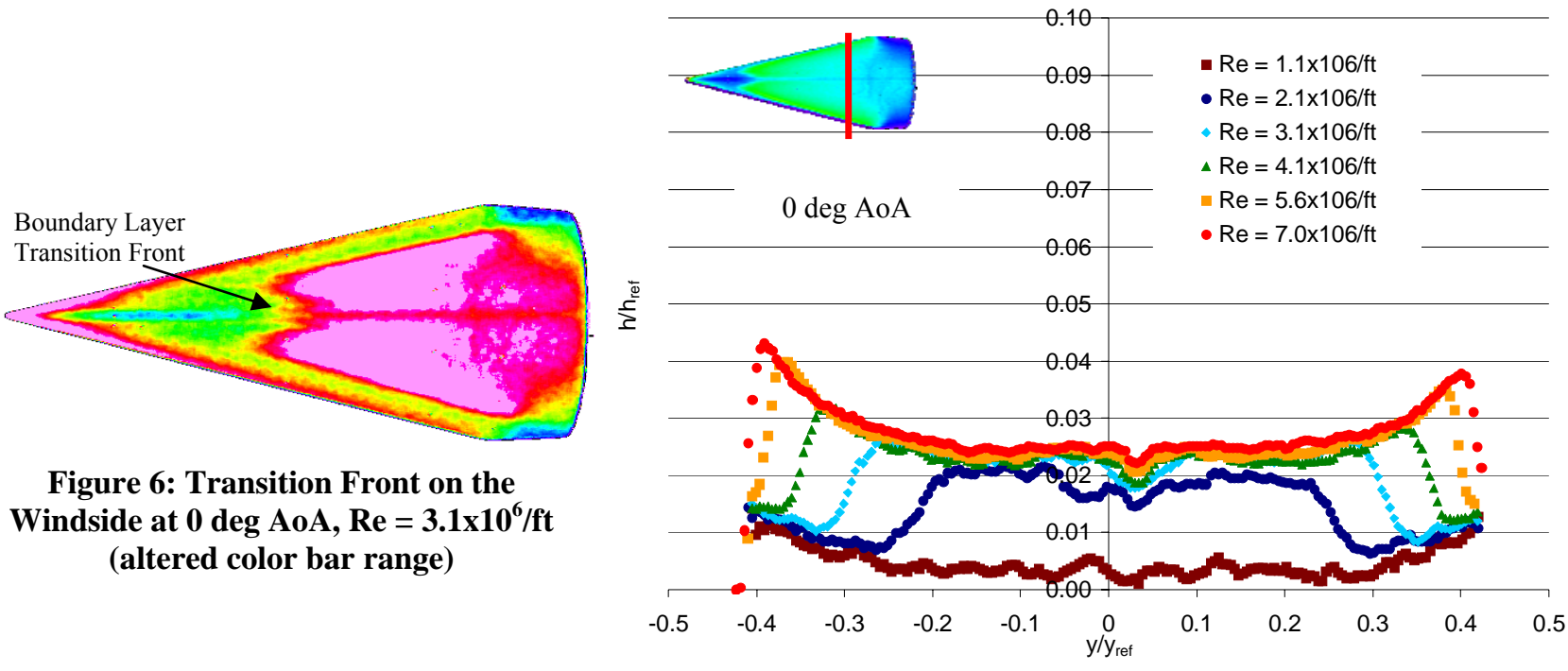

Figure 7: Spanwise Heating at $\mathrm{x} / \mathrm{L}=0.7$

As the angle of attack is increased, the centerline boundary layer transition becomes more evident and the transition pattern changes from a two- to three-lobed pattern. As shown in Fig. 8, at -4 deg AoA, the leeside heating (discussed in the next section) is in a double lobe around the centerline. At -2 deg AoA, the two-lobe pattern becomes stronger and continues to develop more at 0 deg AoA. At 2 deg AoA (windward), a small centerline lobe becomes evident and is roughly inducing transition at the same $\mathrm{x} / \mathrm{L}$ location as the off-centerline transition. As the angle of attack is further increased to $4 \mathrm{deg}$, the centerline transition becomes more evident and transitions forward of the off-centerline region. This pattern is indicative of the switch from in-flow towards out-flow as the angle of attack is increased for the model and is similar to the patterns exhibited on vehicles such as the X-33 in Ref. 26.

Significant effort was spent on the boundary layer transition tripping on the windward surface of the HIFiRE 5 model. At 0 deg AoA, none of the boundary layer trips utilized (ranging from 0.0035 to 0.0185 in.) were able to induce boundary layer transition on the centerline of the model. Both 2-D (strip to represent joints on the vehicle) and 3-D (diamond shaped to represent the fasteners on the closeout panel of the vehicle) trips were tried. Some localized increases in heating were evident in Fig. 9 immediately aft of the trip but the flow quickly returned to the un-tripped heating levels. It should be noted that the natural boundary layer transition onset for the case shown (unit Reynolds number of $5.6 \times 10^{6} / \mathrm{ft}$ ) is very close to the trip location. For other, lower, unit Reynolds numbers tested, the natural transition locations move aft on the model and the same pattern of a localized increase in heating followed by the return to un-tripped heating levels is repeated (not shown). As expected for the centerline, at no point was 
transition measured immediately at the site of the trip (fully effective). It is evident from the heating images as well as Fig. 10 (axial set of data from the same conditions as Fig. 9) that while there seemed to be very little effect of the trip on the centerline, there was significant effect on the leading edges of the model (2-D trips) and off-centerline (3$\mathrm{D}$ trips). The 2-D trips did not have a significant effect on the cross-flow transition regions previously identified offcenterline.
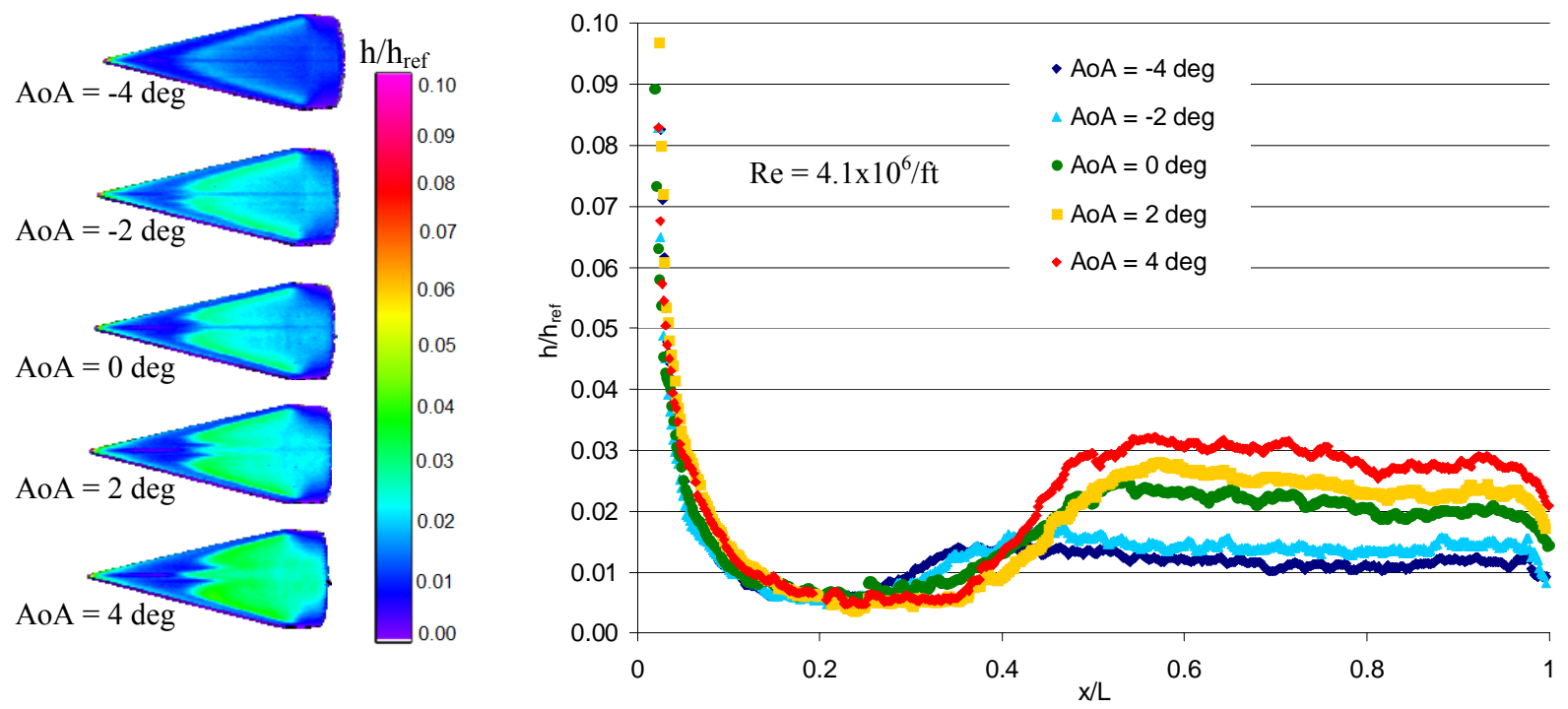

Figure 8: Angle of Attack Effects
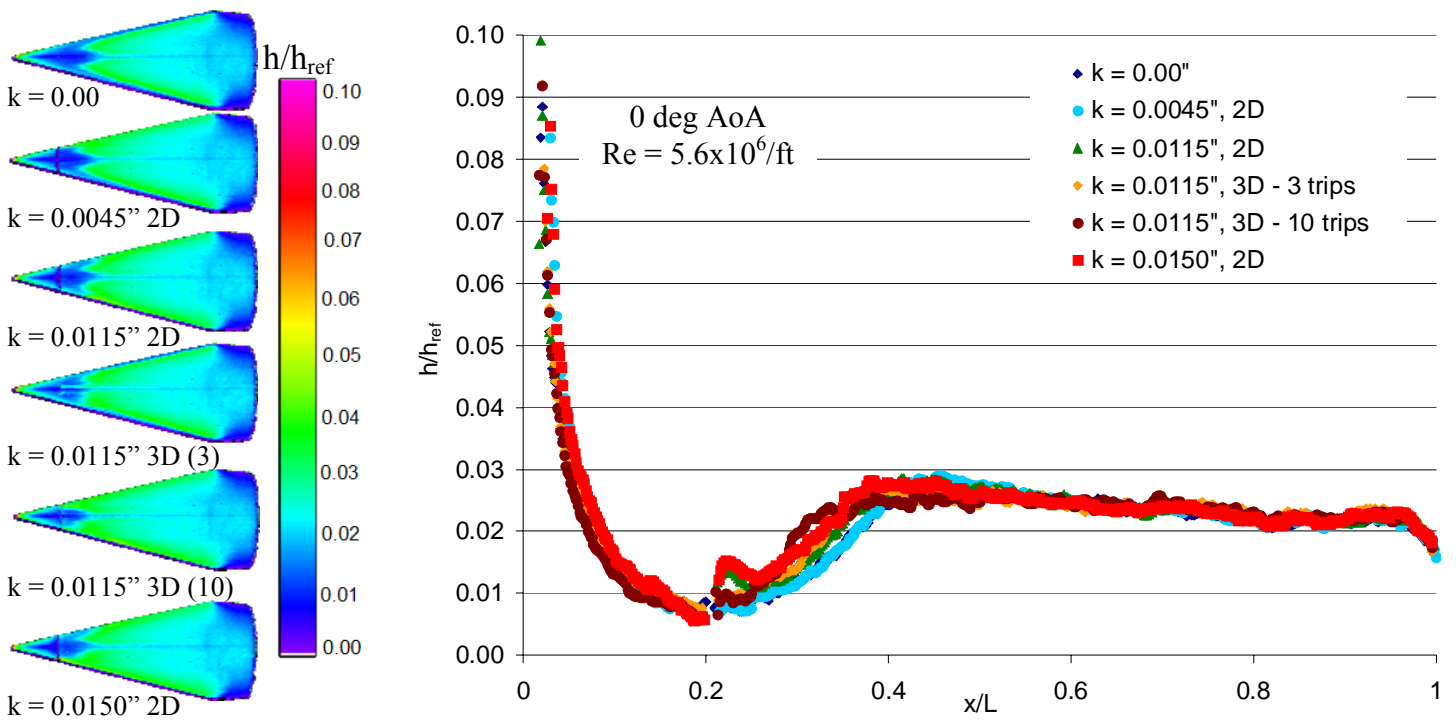

Figure 9: Centerline Tripped Heating Data

An attempt was made to quantify the range of critical boundary layer trip height (the smallest roughness that affects the boundary layer transition onset location) at two unit Reynolds numbers, 4.0 and $5.6 \times 10^{6} / \mathrm{ft}$. Various boundary layer trip heights were tested at $0 \mathrm{deg}$ AoA and 0 deg sideslip. The maximum value of the range (see Table 2 for windside surface results) is associated with the smallest trip height that caused boundary layer transition onset. The minimum value stated is associated with the next smallest trip tested, as that trip height did not cause a departure from the laminar heating levels. For the unit Reynolds number of $4.0 \times 10^{6} / \mathrm{ft}$, the critical trip height is between 0.0105 and $0.0140 \mathrm{in}$. and for $5.6 \times 10^{6} / \mathrm{ft}$, the critical trip is between 0.0045 and $0.0115 \mathrm{in}$. when using the 2D trip shape. 


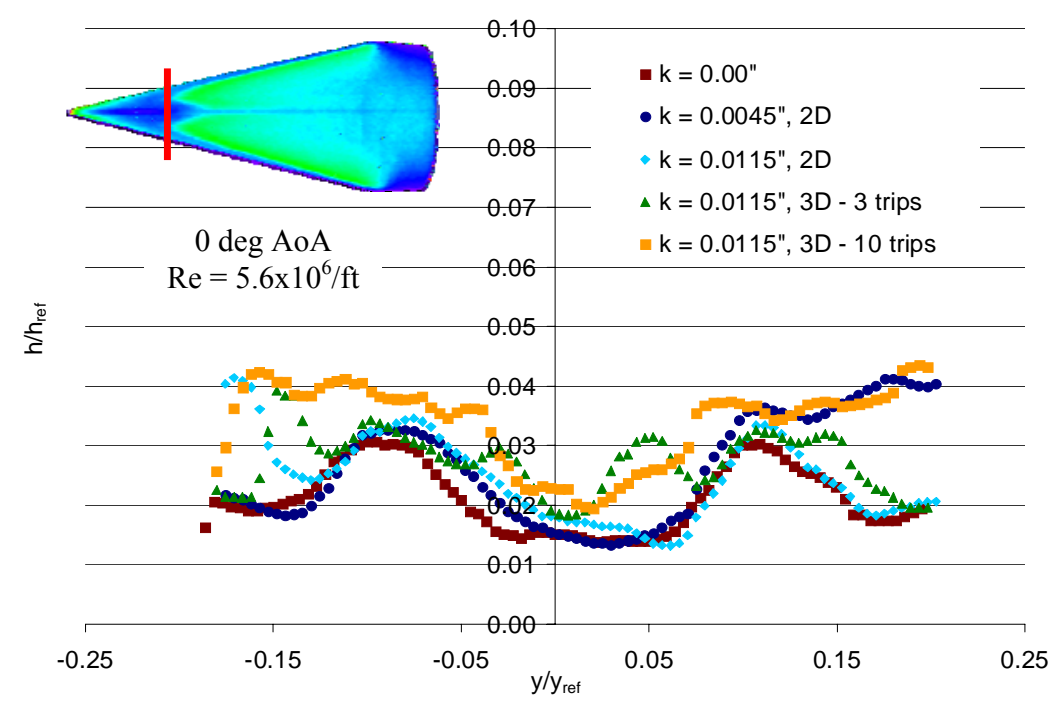

Figure 10: Boundary Layer Trip Effectiveness at $\mathrm{x} / \mathrm{L}=0.325$

Table 2: Critical Boundary Layer Trip Height for the Windward Surface (0 deg AoA, 0 deg Sideslip)

\begin{tabular}{|c|c|c|c|}
\hline $\begin{array}{c}\text { Unit Reynolds } \\
\text { Number }\left(\times 10^{6} / \mathrm{ft}\right)\end{array}$ & Trip Geometry & $\begin{array}{c}\text { Minimum Critical Height } \\
\text { (in) }\end{array}$ & $\begin{array}{c}\text { Maximum Critical Height } \\
\text { (in) }\end{array}$ \\
\hline 4.0 & 2D (strip) & 0.0105 & 0.0140 \\
\hline 5.6 & 2D (strip) & 0.0045 & 0.0115 \\
\hline
\end{tabular}

The 2-D trips had a more significant effect both on and off of the centerline at angle of attack, probably because of thinner boundary layers. When the model was pitched to 4 deg AoA, the 2-D trips caused a shift forward in the onset of centerline boundary layer transition as well as transition on the leading edges is shown in Fig. 11. Increasing the trip height moved the transition onset location further forward on the model.

Reduction of the trip heights to transitional correlating parameters will be the subject of future work.
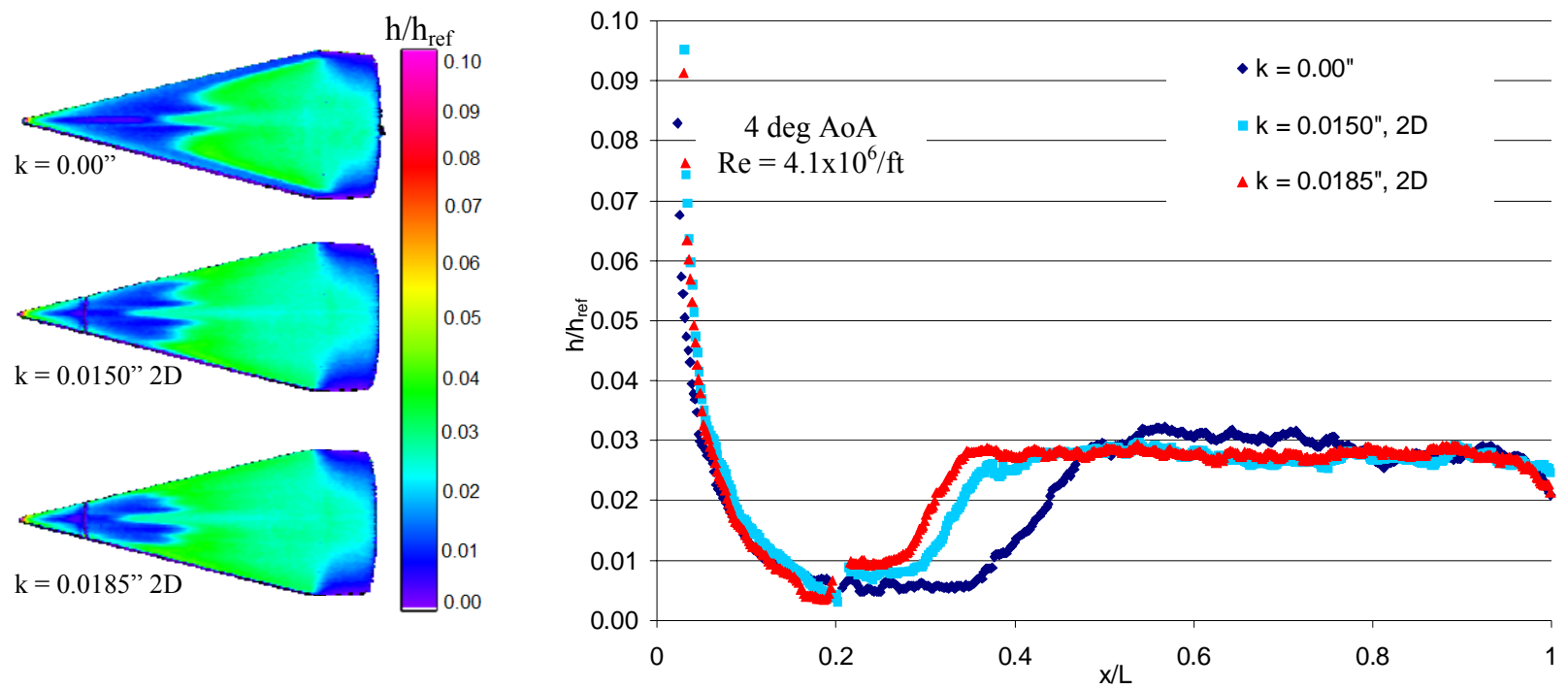

Figure 11: Effect of Trips Windside Heating at Angle of Attack

A concern for the flight vehicle is the potential contamination of flight data on the smooth, clean side by augmented heating associated with the access-panel closure hardware on the other side of the flight vehicle. For this reason, discrete boundary layer trips were tested at various locations on the windward surface in an attempt to understand the spreading characteristics of the turbulent wedge associated with the trip. Three locations were 
initially tested, to be referred to as centerline, Trip Location 1 and Trip Location 2. See Fig. 12 for a diagram of trip locations. All three trips were at $\mathrm{x} / \mathrm{L}=0.2$. The Trip Location 1 was 0.23 in. off the centerline and the Trip Location 2 was 0.35 in. off the centerline. The centerline trips were not found to cause boundary layer transition at any conditions and will not be discussed further. The Trip Locations 1 and 2 did result in visible disturbances at most conditions though the effects were more significant at increased angle of attack. A large trip was utilized $(\mathrm{k}=0.0185$ in.) in order to ensure the maximum possibility of resulting in non-laminar heating. No study was completed on the effect of trip height. In all cases, the augmented heating did not spread to the leading edge of the model far enough upstream to affect the opposite side of the elliptical cone. This lack or turbulent heating spreading from one side to the other indicates that the hardware on the closeout panel side of the flight vehicle would not influence the heating on the "clean" side of the vehicle.
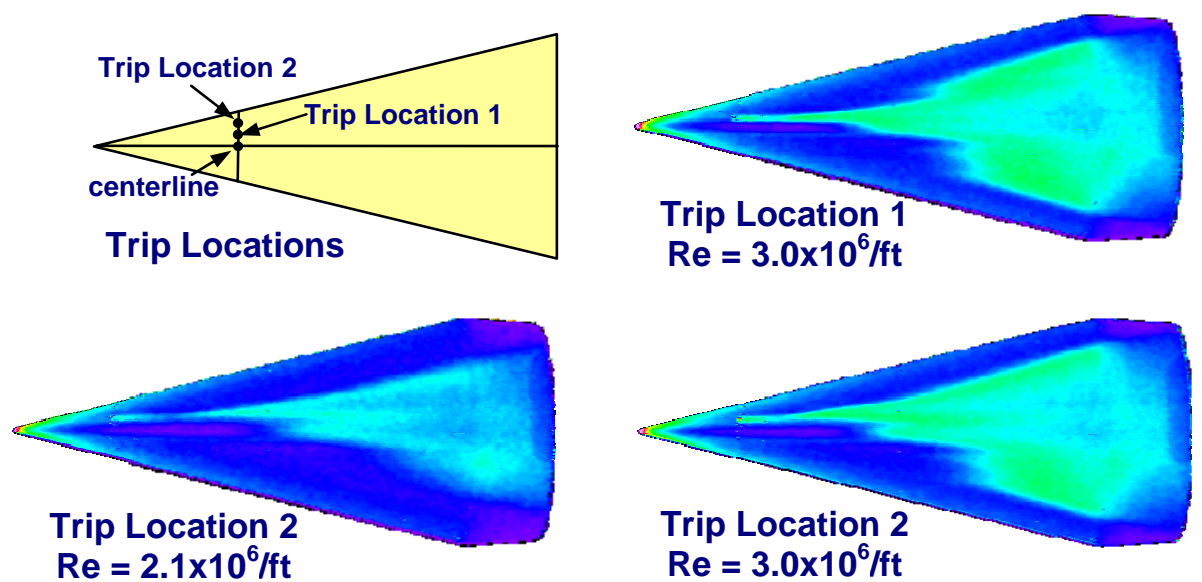

Figure 12: Spreading Angles from Discrete Trips on the Windward Surface, 4 deg AoA

\section{Leeside Heating}

Leeside surface heating and boundary layer transition characteristics of the HIFiRE 5 vehicle were required as a part of the ground test program. No boundary layer tripping was done for the leeside surface and -2 and -4 deg AoA were tested with 0 deg sideslip. A variety of unit Reynolds numbers were run in order to characterize the natural boundary layer transition patterns for the leeside surface. As shown in Fig. 13, there appears to be turbulent heating on the body of the model, with the departure from laminar heating occurring earlier as the unit Reynolds number is increased. Elevated heating due to transition occurs off-centerline, as shown in the global image. The double-lobed transition pattern is similar to that observed on the model at zero deg AoA, and suggests that crossflow is the dominant transition mechanism on the leeside.
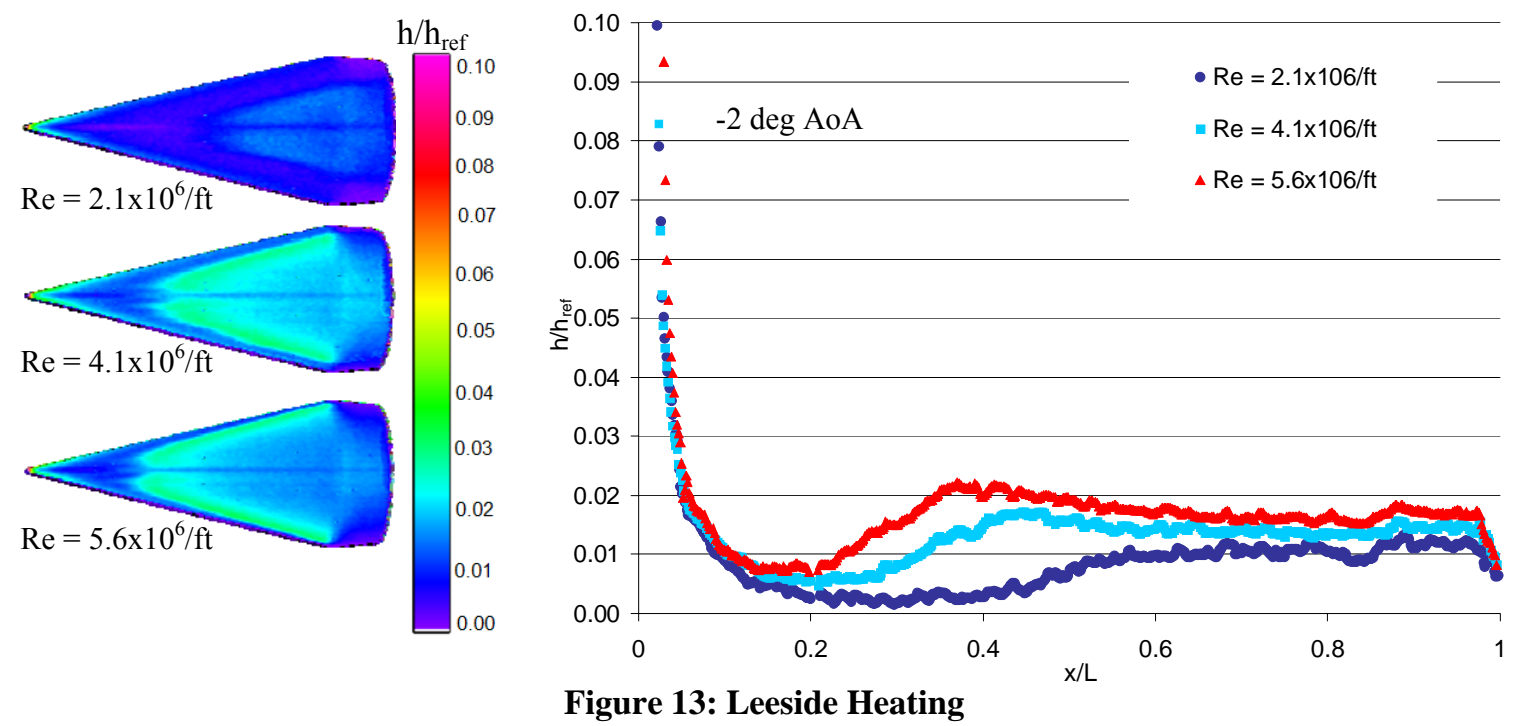
Leading Edge Heating

Heating and boundary layer transition characteristics of the leading edge of the model were determined. The baseline shape was tested extensively to determine the effects of natural and forced boundary layer transition. Initial testing indicated that in the absence of boundary layer trips, the leading edge would naturally transition at a unit Reynolds number of $5.3 \times 10^{6} / \mathrm{ft}$, shown in Fig. 14. The turbulent or non-laminar heating associated with the windside and leeside of the model do not contaminate the centerline of the side surface below $\operatorname{Re}=5.3 \times 10^{6} / \mathrm{ft}$ for the zero deg AoA case. This unit Reynolds number value was used for the remainder of the testing as the target unit Reynolds number for the side surface. A boundary layer trip was considered to be critical if it caused deviation from the laminar heating profile at this unit Reynolds number. In all cases the smooth leading edge transition appears downstream from the centerline transition and appears to result from a smooth merger of the turbulent fields on the top and bottom of the model. This transition pattern is in contrast to a distinct leading-edge-first transition observed in some cases in tests at CUBRC ${ }^{27}$. The cause of this difference in transition behavior between the current tests and CUBRC tests is unclear at this point.
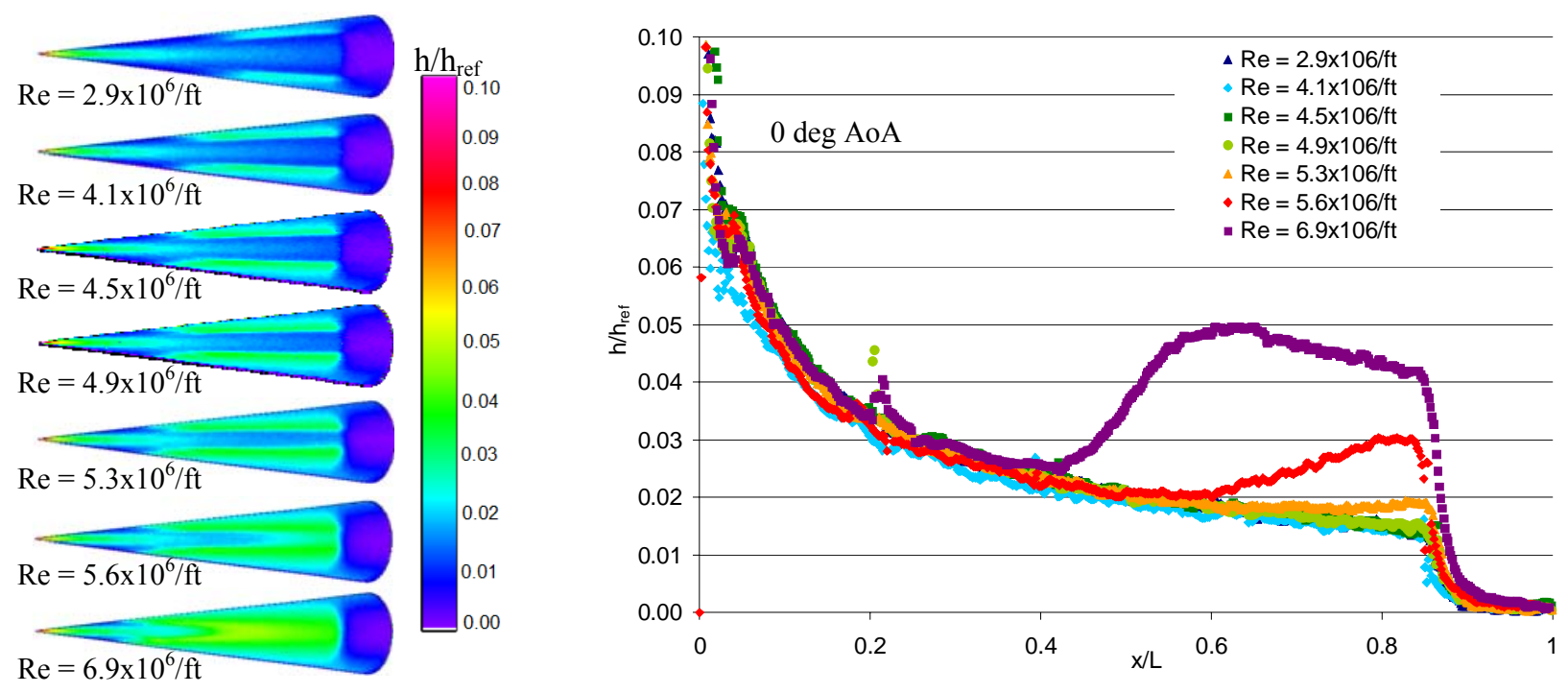

Figure 14: Leading Edge Heating

Just as on the windside surface, the side surface was tested with a variety of boundary layer trips to determine the range of trip effectiveness. The focus was primarily on the 2-D ("strip") trips to represent joints between the nose and body sections of the vehicle and secondarily on the 3-D ("diamond") trips to represent fasteners on a closeout panel on the vehicle, as the 3D trip is not likely on the flight vehicle leading edge. Testing was completed at

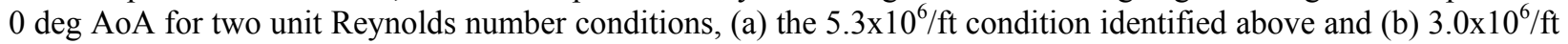
to match the maximum quiet-flow Reynolds number in Purdue University's Mach 6 Quiet Tunnel and allow for future tunnel-to-tunnel comparisons. As shown in Fig. 15, for the 2D trips with a unit Reynolds number of $5.3 \times 10^{6} / \mathrm{ft}$, the critical boundary layer trip height was found to be between $\mathrm{k}=0.0090$ and $0.0115 \mathrm{in}$. The ranges determined for this case and the other three cases are summarized in Table 3. At the unit Reynolds number of $5.3 \times 10^{6} / \mathrm{ft}$ case with the 3 -D trips, the smallest boundary layer trip tested $(\mathrm{k}=0.0025 \mathrm{in}$.) caused boundary layer transition, and no smaller boundary layer trips were available. In an attempt to further bound the values and in the absence of smaller trips, the trip was placed further aft on the model $(\mathrm{x} / \mathrm{L}$ of 0.5 as opposed to 0.2 for the rest of the boundary layer trip testing). Even at this farther aft location the $\mathrm{k}=0.0025$ in. trip did cause boundary layer transition onset, as noted from the departure from the laminar centerline heating in Fig. 16. No further investigation was done. At the lower unit Reynolds number condition $\left(\mathrm{Re}=3.0 \times 10^{6} / \mathrm{ft}\right)$, the critical boundary layer trip height was between $0.0045-0.0080 \mathrm{in}$. for the 3-D trip case and 0.0150-0.0185 in. for the 2-D trip case. It is clear from this testing that the 3-D trip is more effective than the 2-D shape but the $2 \mathrm{D}$ trip is the shape expected on the flight vehicle leading edge. 

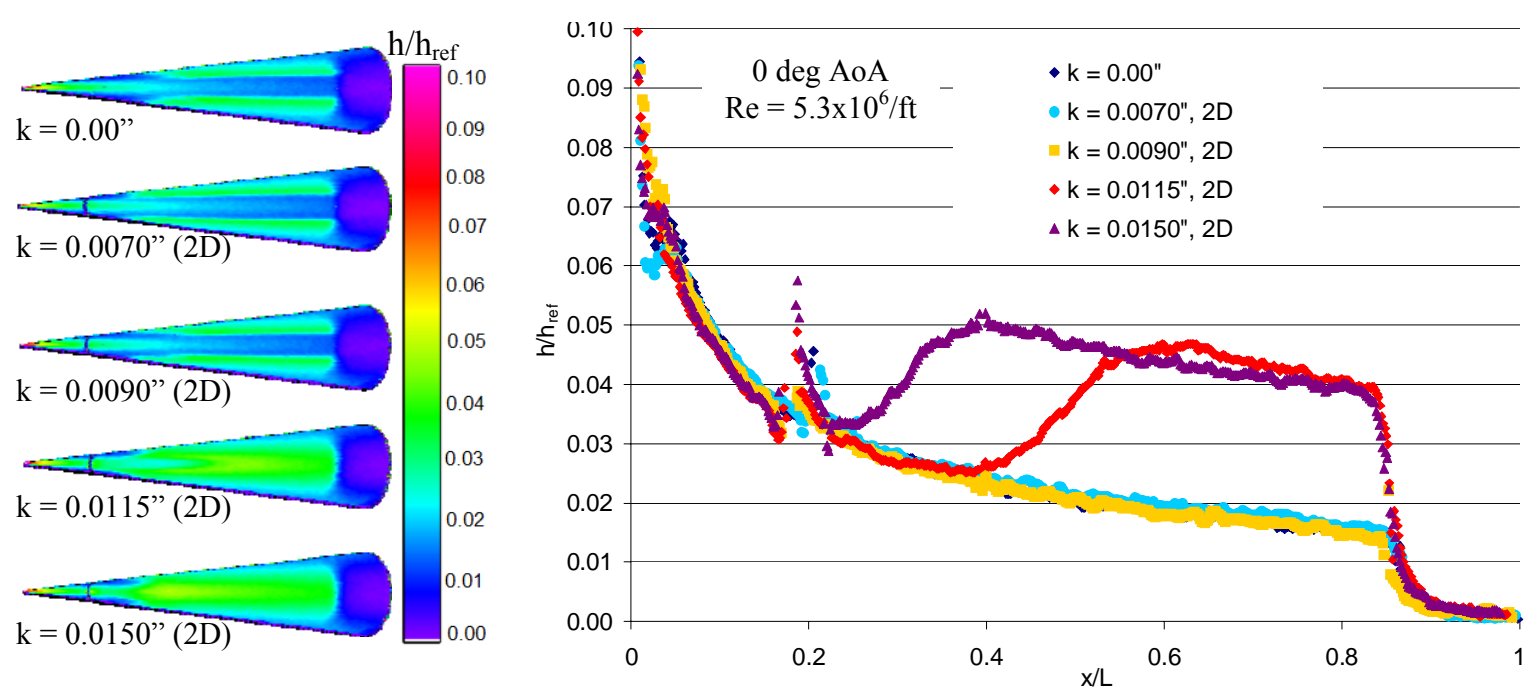

Figure 15: 2D Boundary Layer Trip Effects on Leading Edge Centerline Heating

Table 3: Critical Boundary Layer Trip Height for the Leading Edge Surface

\begin{tabular}{|c|c|c|c|c|}
\hline $\begin{array}{c}\text { Unit Reynolds } \\
\text { Number }\left(\mathrm{x} 10^{6} / \mathrm{ft}\right)\end{array}$ & $\begin{array}{c}\text { Beta } \\
(\mathrm{deg})\end{array}$ & Trip Geometry & $\begin{array}{c}\text { Minimum Critical Height } \\
\text { (in) }\end{array}$ & $\begin{array}{c}\text { Maximum Critical Height } \\
\text { (in) }\end{array}$ \\
\hline 3.0 & 0 & 3D (diamond) & 0.0045 & 0.0080 \\
\hline 3.0 & 0 & 2D (strip) & 0.0150 & 0.0185 \\
\hline 5.3 & 0 & 3D (diamond) & NA & 0.0025 \\
\hline 5.3 & 0 & 2D (strip) & 0.0090 & 0.0115 \\
\hline 5.6 & 4 & 2D (strip) & 0.0090 & 0.0125 \\
\hline
\end{tabular}
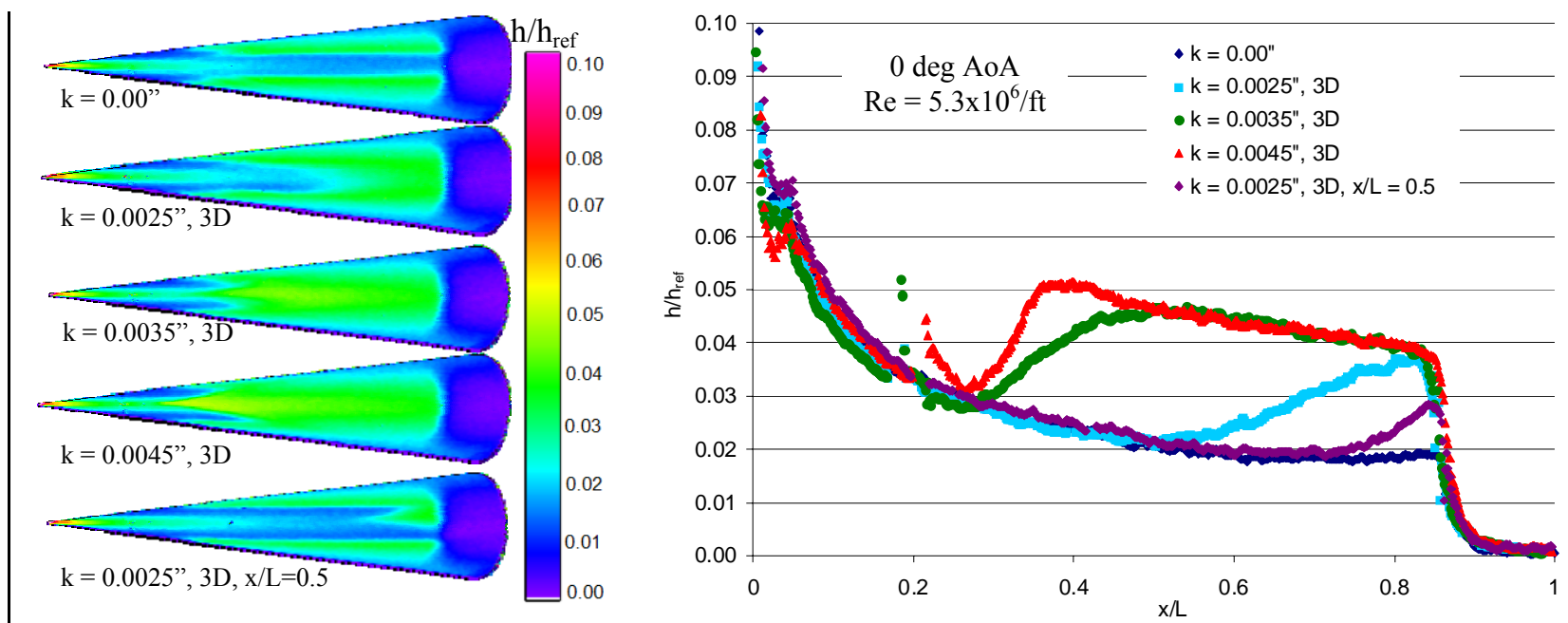

Figure 16: 3D Trip Effectiveness for the Leading Edge [trips at $\mathrm{x} / \mathrm{L}=0.2$ unless noted]

\section{Effect of Sideslip Angle}

A brief study in the effect of sideslip angle on the leading edge heating was done and the model was tested at -4 , 0 and 4 deg sideslip. All three cases were tripped with a 0.0125 in. 2 -D trip at $\operatorname{Re}=5.6 \times 10^{6} / \mathrm{ft}$ (except for the 0 deg case where the closest trip size was 0.0115 in. at a unit Reynolds number of $5.3 \times 10^{6} / \mathrm{ft}$.). As shown in Fig. 17, the centerline transitioned at all of the sideslip angles but boundary layer transition moves significantly forward at a sideslip of $+4 \mathrm{deg}$. At a sideslip angle of $-4 \mathrm{deg}$, the transitional/turbulent leading edge heating appears to result from a smooth merger of the turbulent fields on the top and bottom of the model. The appearance of the leading edge transition in this case is different from the zero AoA tripped case, and the leading edge transition does not appear to be the result of the trip at -4 deg sideslip. 
At the sideslip +4 deg case, a boundary layer tripping study varying the trip height was completed at a unit Reynolds number of $5.6 \times 10^{6} / \mathrm{ft}$ and $0 \mathrm{deg}$ AoA. As shown in Fig. 18, the $\mathrm{k}=0.0090 \mathrm{in}$. trip did not cause a departure from the laminar heating. When the $\mathrm{k}=0.0125$ in. trip was used, the flow transitioned very quickly and close to the trip location. No testing was done in order to further refine the range.
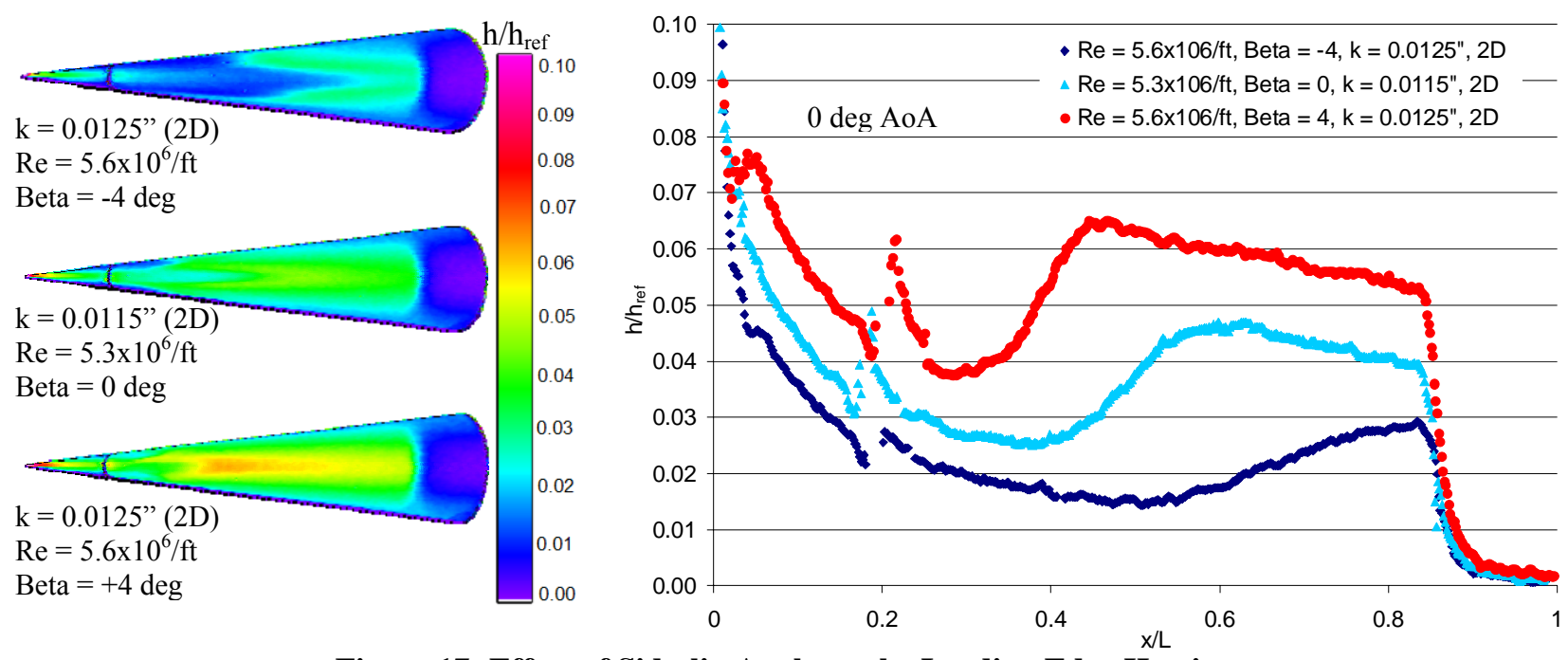

Figure 17: Effect of Sideslip Angle on the Leading Edge Heating
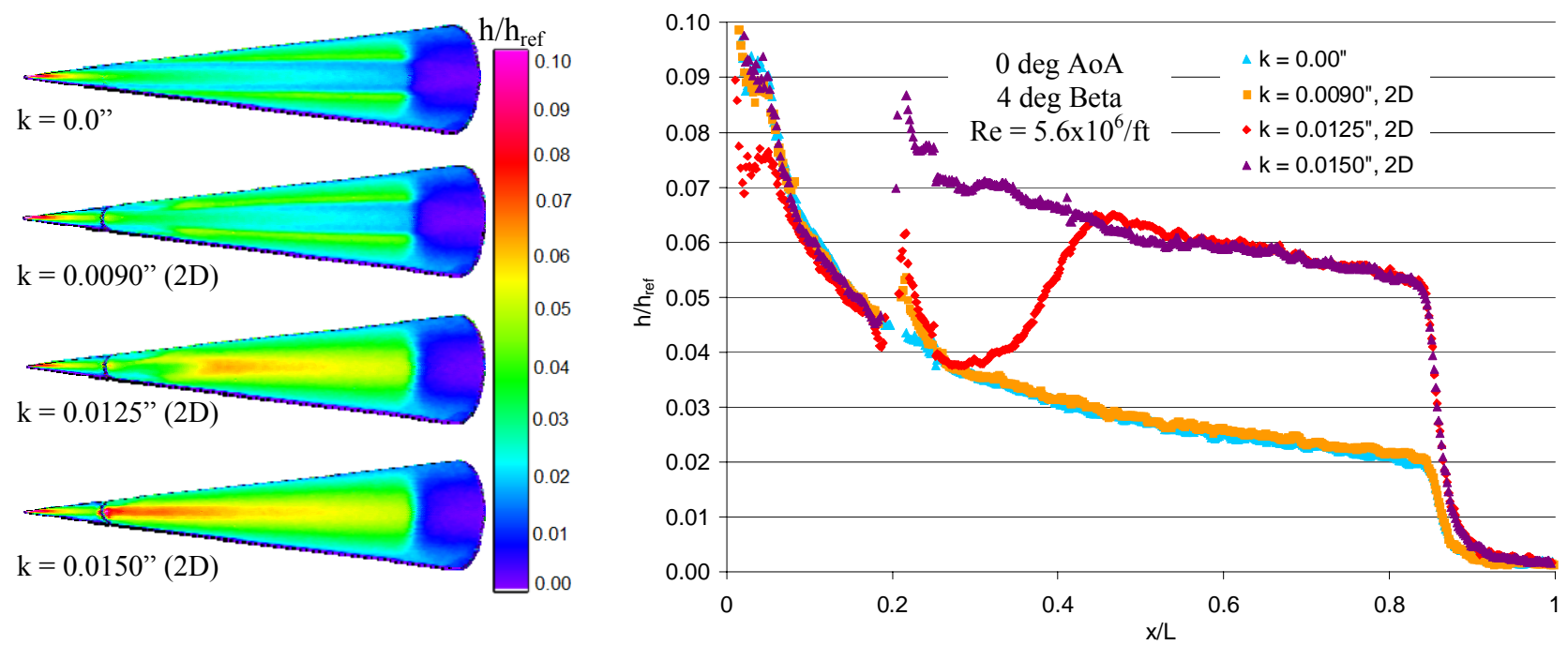

Figure 18: Boundary Layer Trip Effectiveness for the Side Surface

\section{Conclusions}

A scaled model of the HIFiRE Flight 5 vehicle was assessed in the Langley Research Center's 20-Inch Mach 6 Tunnel. The primary objectives of this test were to determine the boundary layer transition characteristics as well as the effectiveness of 2-D strip trips to simulate the joint between the nosecap and body of the vehicle and 3-D diamond shaped trips, to simulate the fasteners on a closeout panel that will be on one side of the flight vehicle. The data will be used to determine if the augmented heating associated with the fasteners and steps on the vehicle will contaminate the smooth side of the vehicle's data as well as for code calibration and for comparison to future testing in other facilities. In order to accomplish this, global heat transfer images were obtained for unit Reynolds numbers of $1.1 \times 10^{6} / \mathrm{ft}$ to $7.0 \times 10^{6} / \mathrm{ft}$, angles of attack of -4 to +4 deg and side slip angles of -4 to $+4 \mathrm{deg}$, which were conditions pertinent to the flight. Heating data demonstrated that the vehicle can be expected to exhibit natural boundary layer transition on the windside surface in the absence of boundary layer trips. The primary driver of the transition at 0 deg AoA appears to be cross-flow boundary layer transition, but windward centerline transition 
becomes more prominent as the angle of attack is increased. On the windside surface, both the 2D and 3D trips were utilized. None of the trips used were able to induce boundary layer transition along the centerline of the windside, though some did cause a local disturbance before the flow returned to the untripped heating levels. Off centerline, the 2D trips were able to significantly influence the leading edges of the model but had little effect on the rest of the model. The 3D trips were much more effective at causing localized turbulent heating, especially as they were moved away from the centerline. The localized, disturbed flow resulting from the 3D trips did not spread around the leading edges of the model and thus attachment hardware on the closeout side of the flight vehicle is not likely to influence the heating on the smooth, "clean" side of the vehicle.

The heating along the leading edge was investigated and the effectiveness of both the 2D and 3D trips were determined. The natural boundary layer transition unit Reynolds number was determined and it was found that the 3D trips were much more effective on the leading edge. Because the most likely cause of premature transition in this region is from the $2 \mathrm{D}$ trip associated with the joint between the nose and the body, much more effort was put into determining the allowable range of trip heights. For the $2 \mathrm{D}$ trips at a unit Reynolds number of $5.3 \times 10^{6} / \mathrm{ft}$ (where natural transition occurred), the critical trip height was between 0.0090 and $0.0115 \mathrm{in}$. and for $3.0 \times 10^{6} / \mathrm{ft}$ it was 0.0150 and $0.0185 \mathrm{in}$. The sideslip angle greatly influenced the transition onset location and increases in the angle moved the transition forward on the model.

In future work, boundary layer profiles will be extracted from Navier-Stokes calculations of the flow field. These will be used to assess trip heights in terms of typical trip correlating parameters. The smooth-body transition patterns will be compared to those calculated using Parabolized Stability Equations. Tripped and possibly smoothbody transition will be compared to results from the Purdue Mach 6 quiet tunnel.

\section{Acknowledgements}

The authors would like to thank the following people for their contributions to the project: Gary Wainwright, Mike Powers, Mark Griffith, Ed Covington and Pete Veneris for their assistance in model design, fabrication and preparation; Grace Gleason, Paul Tucker, and Mike Holloway for wind tunnel support; Kevin Hollingsworth and Teck-Sen Kwa for data acquisition assistance; Vincent Zoby for assistance in data interpretation and understanding; Without their help, these tests would not have been possible.

\section{References}

1 Reed, H. L., Kimmel, R. L., Schneider, S., Arnal, D., and Saric, W., "Drag Prediction and Transition in Hypersonic Flow," AGARD Paper C-15, Symposium on Sustained Hypersonic Flight, AGARD Conference on Future Aerospace Technology in the Service of the Alliance, 14-17 April 1997, Ecole Polytechnique, Palaiseau, France.

2 Whitehead, A., "NASP Aerodynamics," AIAA paper 89-5013, July 1989.

3 Kimmel, R. L., and Poggie, J., "Transition on an Elliptic Cone at Mach 8," American Society of Mechanical Engineers ASME FEDSM97-3111, June 1997.

4 Kimmel, R. L., and Poggie, J., "Three-Dimensional Hypersonic Boundary Layer Stability and Transition," Air Force Research Laboratory Technical Report, WL-TR-97-3111, December 1997, Wright-Patterson Air Force Base, Ohio.

5 Kimmel, R. L., and Poggie, J., Schwoerke, S. N., "Laminar-Turbulent Transition in a Mach 8 Elliptic Cone Flow," AIAA Journal, vol. 37, no. 9, Sep. 1999, pp. 1080-1087.

6 Schmisseur, J. D., "Receptivity of the Boundary Layer on a Mach-4 Elliptic Cone to Laser-Generated Localized Freestream Perturbations," Doctoral Dissertation, Purdue University Aerospace Sciences Laboratory, December 1997.

7 Holden, M., "Experimental Studies of Laminar, Transitional, and Turbulent Hypersonic Flows Over Elliptic Cones at Angle of Attack," Air Force Office of Scientific Research Technical Report AFRL-SR-BL-TR-980142, Bolling Air Force Base, DC, 1998.

8 Schmisseur, J. D., Schneider, S. P., and Collicott, S. H., "Receptivity of the Mach 4 Boundary Layer on an Elliptic Cone to Laser-Generated Localized Freestream Perturbations," AIAA paper 1998-0532, January 1998.

9 Schmisseur, J. D., Schneider, S. P., and Collicott, S. H., "Response of the Mach 4 boundary layer on an elliptic cone to laser-generated freestream perturbations," AIAA paper 1999-0410, January 1999.

10 Lyttle, I. J., and Reed, H. L., "Use of Transition Correlations for Three-Dimensional Boundary Layers Within Hypersonic Flows," AIAA-95-2293, June 1995.

11 Kimmel, R. L., Klein, M. A., and Schwoerke, S. N., "Three-Dimensional Hypersonic Laminar Boundary Layer Computations for Transition Experiment Design," AIAA Journal of Spacecraft and Rockets, vol. 34, no. 4, JulyAugust 1997 
12 Kimmel, R. L., “Aspects of Hypersonic Boundary Layer Transition Control,” AIAA Paper 2003-0772, January 2003.

13 Stetson, K. F., Thompson, E. R., Donaldson, J. C., and Siler, L. G., "Laminar Boundary Layer Stability Experiments on a Cone at Mach 8, Part 5: Tests with a Cooled Model," AIAA 89-1895, June 1989.

14 Choudhari, M., Chang, C., Li, F., McGinley, C., Berger, K., Candler, G., Kimmel, R., "Transition Analysis for the HIFiRE-5 Vehicle," AIAA-2009-4056, June 2009.

15 Berger, K. T., Greene, F. A., Kimmel, R., “Aerothermodynamic Testing and Boundary Layer Trip Sizing of the HIFiRE Flight 1 Vehicle.” AIAA-2008-640, January 2008.

16 Johnson, H. B., Alba, C. R., Candler, G. V., MacLean, M., Wadhams, T, and Holden, M. "Boundary Layer Stability Analysis to Support the HIFiRE Transition Experiment," AIAA-2007-0311, January 2007.

17 Alba, C., Johnson, H. and Candler, G., "Boundary Layer Stability Calculations of the HIFiRE Flight 1 Vehicle in the LaRC 20- Inch Mach 6 Air Tunnel,” AIAA-2008-0505, January 2008

18 Kimmel, R. L., Adamczak, D., Gaitonde, D., Rougeux, A., Hayes, J. R., "HIFiRE-1 Boundary Layer Transition Experiment Design," AIAA-2007-0534, January 2007.

19 Wadhams, T. P., MacLean, M. G., Holden, M.S., and Mundy, E., "Pre-Flight Ground Testing of the Full-Scale FRESH FX-1 at Fully Duplicated Flight Conditions,” AIAA- 2007-4488, June 2007

20 Horvath, T. J., et al, "Shuttle Damage/Repair from the Perspective of Hypersonic Boundary Layer Transition Experimental Results," AIAA 2006-2919, June 2006.

21 Micol, J. R., "Langley aerothermodynamics facilities complex: enhancements and testing capabilities," AIAA Paper 98-0147, Jan 1998.

22 Buck, G. M., "Automated thermal mapping techniques using chromatic image analysis," NASA TM 101554, April 1989.

23 Merski, N. R., "Reduction and analysis of phosphor thermography data with iheat software package," AIAA-980712, Jan 1998.

24 Merski, N. R., "Global aeroheating wind-tunnel measurements using improved two-color phosphor thermography model," Journal of Spacecraft and Rockets, Vol., 36, No., 2, 1998, pp. 160-170.

25 Fay, J. A., and Riddell, F. R., "Theory of Stagnation Point Heat Transfer in Dissociated Air," Journal of Aeronautical Sciences, Vol. 25, No. 2, 1958, pp. 73-85.

26 Horvath, T. J., Berry, S. A., Hollis, B. R., Liechty, D. S., Hamilton, H. H., Merski, N. R., "X-33 Experimental Aeroheating at Mach 6 Using Phosphor Thermography," AIAA Journal of Spacecraft and Rockets, vol. 38, no. 5, 2001, pp. 634-645.

27 Holden, M. S., Wadhams, T. P., MacLean, M. Mundy, E., "Review of Studies of Boundary Layer Transition in Hypersonic Flows Over Axisymmetric and Elliptic Cones Conducted in the CUBRC Shock Tunnels, AIAA paper 2009-0782, January 2009. 